\title{
Dietary energy density on using sugar alcohols as replacements for sugars
}

\author{
BY AREN J. H. VAN ES \\ Retired from Department of Human and Animal Physiology, 10 Haarweg, 6709PJ Wageningen, \\ The Netherlands
}

The sweet taste was appreciated by man long ago: sugar cane was grown 2000 years ago in India and in 1550 was already an important crop in some Caribbean islands (Beardsley, 1989). Only recently have we begun to understand how, physiologically, sweetness is experienced by the taste receptors in our mouth (Birch, 1987; Encyclopaedia Britannica, 1987; Beardsley, 1989). Both carbohydrate- and peptide-based sweeteners exist and both seem to have to fit stereometrically to the taste receptors. Two of the five stereomeres of fructose dissolved in water are sweeter than the others; an equilibrium exists between them which is temperature dependent and, thus, influences the sweetness of a fructose drink. Also the taste of peptide-based sweeteners (e.g. aspartame) is related to their stereometric configuration.

Sweeteners differ greatly in sweetness and some recently-developed ones are extremely sweet (aspartame and acesulfame K: 200 times as sweet as sucrose). Most of the sugar alcohols (SA) taste somewhat less sweet than sucrose (sorbitol and mannitol 0.5-0.6-fold, xylitol 1.0-fold, lactitol 0.4-fold, maltitol 0.9-fold, isomalt $0 \cdot 5$-fold).

Replacing sucrose by SA may be done for several reasons (Ziesenitz \& Siebert, 1987): (1) caries prevention; most oral microbes use SA far more slowly than sucrose so that the $\mathrm{pH}$ in the dental plaque remains higher;

(2) slower and less absorption of glucose than from sucrose, which is an advantage to diabetics;

(3) less absorption of utilizable energy, which is of benefit to subjects who become easily overweight.

Another possibly advantageous effect for those SA that reach the large intestine is the stimulation of microbial fermentation in that part of the gut. This may lead to shorter transit times for digesta due to the osmotic properties of the SA and of their degradation products, the volatile fatty acids (VFA), and lead to a greater supply of butyric acid, to a lower $\mathrm{pH}$ and possibly to some neutralization of free radicals (Gibson et al. 1988; Henderson \& Demeyer, 1988; Bergman, 1990). However, too much fermentation might give excessive gas formation, diarrhoea and, possibly, undesirable nitrate and sulphate reduction (Grimble, 1989). In view of possible discomfort it is often advised (Nutrition Council, 1987) to ingest, preferably in several small portions, not more than $20 \mathrm{~g} \mathrm{SA}$ daily, although many individuals can consume more without complaint, especially after adaptation. It may be questioned if at that intake level $(20 \mathrm{~g} / \mathrm{d})$, the benefit of the lower intake of utilizable energy as compared with a similar sucrose intake $(20 \mathrm{~g} / \mathrm{d}$; less than $1.5 \%$ of man's daily energy requirement) will help to prevent obesity.

In fact man's regulation of energy intake is extremely precise; many adults maintain their body-weight remarkably well, although even an excess of only $1 \%$ of energy intake over energy requirement during 1 year would result in a weight gain of $1-1.5 \mathrm{~kg}$ (James et al. 1990). Also ad lib.-fed farm animals usually regulate their energy intake in such a way that they do not become too lean or too obese (Forbes, 1986). Only when older, 
when fed on a very palatable feed and when restricted in physical activity, a situation not uncommon to man, do they tend to become obese. Thus, even a small reduction of energy intake of $1-2 \%$ due to replacing part of sucrose by SA may help to maintain equilibrium between energy intake and energy requirement and so body-weight in man. The slight increase of gas formation after SA intake also may lower appetite somewhat; however, the lower sweetness of many SA may lead to a higher than a 1:1 (w/w) partial replacement of sucrose. Unfortunately, for practical reasons, it is impossible to measure the long-term effect of even such a $1: 1(\mathrm{w} / \mathrm{w})$ partial replacement on man's energy equilibrium with sufficient precision.

\section{DIGESTION AND METABOLISM OF SA}

Three aspects of the absorption and utilization of energy resulting from intake of SA have to be discussed:

(1) absorption from the small intestine,

(2) absorption from the large intestine,

(3) utilization of absorbed nutrients through intermediary metabolism.

Attention will be paid, mainly from a point of view of energy utilization, to the various methods used to quantify these items and to problems of reaching a sufficient precision when SA is ingested at the recommended low level of $20 \mathrm{~g} / \mathrm{d}$, i.e. an amount of gross energy of only $3-4 \%$ of man's daily energy requirement. In his recent Editorial, Gurr (1990) mentioned the many methodological difficulties and problems of correct interpretation of such and related investigations.

Absorption from the small intestine. Information comes from studies using subjects having an ileostomy or a triple-lumen tube from mouth to the end of the ileum, with pigs with a cannula at the end of the ileum and with germ-free animals, and from studies on the presence and activity of enzymes and of transport systems of the small intestine (Nilsson \& Jägerstad, 1987; Nutrition Council, 1987; Ziesenitz \& Siebert, 1987; Beaugerie et al. 1991).

Whereas in the experiments with man a maintenance diet is usually given, in those with animals often $a d$ lib. or nearly $a d$ lib. feeding is applied resulting in feeding levels of 1.5-2 times maintenance (Van Weerden et al. 1984, 1989; Berschauer, 1985; Grossklaus, 1985). This might increase the rate of digesta passage and may result in lower absorption, especially when the SA lowers transit time because of its osmotic properties.

Usually what is measured is disappearance from the stomach and small intestine rather than absorption. Analysis of the samples is often limited to the SA itself; however, some of its hydrolysis products might still be present at the end of the ileum.

Higher intakes of the SA, $10 \%$ of the gross energy of the diet and more, as often used in animal studies to improve precision, may, in theory, due to the osmotic properties of SA, lead to increased rates of digesta passage and reduced absorption, not only of the SA but also of the diet (Van Weerden et al. 1989). Intake of smaller quantities of SA in liquid form after a fast, without a meal, is also considered to lead to abnormally rapid digesta passage (Livesey, 1989). A potentially very useful procedure is the intubation method, in which a fairly small quantity of SA is given in two portions within $1 \mathrm{~h}$ of a meal. However, taking representative samples of the digesta, especially in the intubation method, but also through a cannula, is far from easy, and analysis of the heterogeneous material may be difficult. 
Water intake of subjects with an ileostomy is usually much lower than in normal subjects and this may affect absorption (Flourié, 1990). Also such subjects often have microbial growth in the ileum leading to fermentation of part of the SA (Dowsett $e t$ al. 1990).

The stomach of the pig differs from that of man, since it contains far more bacteria, as does the ileum (Ratcliffe, 1985; Giesecke, 1990). These microbes easily ferment SA, after their ingestion VFA are always found at the end of the ileum of pigs.

Re-entrant cannulation of the terminal ileum may slow down digesta passage; cannula sampling is usually done over too short periods because of labour costs. T-cannulation affects digesta passage less but gives additional errors of digesta sampling and marker analysis.

The intubation technique in man does not appear to change fluid transport, the possible effect on transport of dissolved and other substances is under study (Flourié, 1990). It is remarkable that this method gave such a high disappearance of sorbitol (79\%) and maltitol (64\%) (Beaugerie et al. 1991).

Work with germ-free animals may be useful; studies suggest that the disappearance of dextrins from the whole gut is the same as in conventional chickens up to the end of the ileum (Szylit \& Charlet, 1981). Würsch et al. (1990) found lower apparent digestibility and utilization of maltitol and sorbitol in germ-free mice than in conventional mice; the SA was given after an overnight fast by stomach tube without a meal.

Studies on enzymes and transport systems of the small intestine can give indications but not precise quantitative information for SA on rate of hydrolysis (if needed) and of absorption.

An indirect method to estimate approximately the absorption of SA from the small intestine consists of comparing the intensity of discomfort due to gas formation and higher defecation frequency caused by the daily intake of various quantities of different SA (Nutrition Council, 1987). It is assumed that the SA and possible hydrolysis products that enter the colon give similar discomfort when degraded by colon microbes regardless of the kind of SA, although this may not be the case.

As none of these methods gives completely reliable results on total energy absorption up to the end of the ileum due to SA intake by man, it is considered that the best that can be done is to carefully interpret all the information together; this was done by the Committee of the Netherlands Nutrition Council in 1987. This Committee (Nutrition Council, 1987) made the following tentative conclusions. All monosaccharide SA are absorbed much more slowly than glucose and, moreover, incompletely. Some results from pigs show that their intake (albeit at a much higher level than $20 \mathrm{~g} / \mathrm{d}$ as in man) leads to a slight increase in flow of the basal diet to the colon. Di- and higher saccharide SA are still more slowly and incompletely absorbed because enzymes for their hydrolysis necessary, before absorption, are lacking or have low activity. With these also there is some evidence of a greater passage of the basal diet into the colon in pigs at rather high SA intake.

Absorption from the large intestine, gas formation and faecal losses. Nearly all SA are readily fermented by microbes in the lower gut. Only traces are found in the faeces which, however, contain small amounts of their degradation products, mainly VFA (Nutrition Council, 1987; Ziesenitz \& Siebert, 1987; Henderson \& Demeyer, 1988; Grimble, 1989; Bergman, 1990; Giesecke, 1990). Faecal energy loss is somewhat higher after SA intake. For the microbes of the lower gut the SA are a good source of energy so 
that they can grow and multiply while using nitrogen from undigested food, enzymes, mucus and possibly urea from the blood for protein synthesis. Much microbial matter is excreted with the faeces, and consists, besides water, mainly of protein and some fat and carbohydrate. Due to lack of oxygen the microbes can obtain only small quantities of energy, ATP, for their metabolism from the conversion of the SA, about ten times less than with aerobic oxidation. This results in a fairly slow rate of growth: anaerobic fermentation therefore takes time.

The main conversion products of fermentation are the VFA (acetate, propionate and butyrate in an approximate molar ratio of 65:20:15), which are easily absorbed in the blood. Intake of large amounts of SA at a time leads also to formation of lactate but this is probably unimportant when intake is $20 \mathrm{~g} / \mathrm{d}$ in several small portions in man. In addition hydrogen, and in many cases methane, and heat of fermentation are produced by the microbes. In man both these gases may be produced, probably from the upper and lower parts of the colon respectively. In the pig usually only $\mathrm{CH}_{4}$ is found because colonic conditions are very suited to methanogenic bacteria and all the $\mathrm{H}_{2}$ produced by other bacteria is used. In some cases in man acetogenic bacteria remove some of the $\mathrm{H}_{2}$ and convert it with carbon dioxide into acetate.

The excretion of microbial matter, $\mathrm{H}_{2}$ and $\mathrm{CH}_{4}$ and the formation of fermentation heat gives an increased energy loss after SA intake. The higher $\mathrm{N}$ excretion with the faeces leads to a lower one with the urine. It might be expected that this would give a lower urinary energy loss. However, in volunteers consuming $50 \mathrm{~g}$ lactitol/d with their diet we did not find less urinary energy (Van Es et al. 1986). Probably also in man microbial fermentation results in a higher urinary excretion of some detoxification products as is well known from studies with herbivores.

From the available information the Nutrition Council's (1987) committee concluded that in man ingesting $20 \mathrm{~g} \mathrm{SA} / \mathrm{d}$ or less, about $20 \%$ of the energy of this sweetener that enters the large intestine would be lost as microbial matter with the faeces and $5-13 \%$ as energy in gases and fermentation heat. The small amount of information obtained since then does not give sufficient reason to change this estimate.

Utilization of the absorbed energy resulting from $S A$ intake in the intermediary metabolism. Most farm animals use much food for production purposes while man's energy metabolism mainly consists of supply and utilization of nutrients for maintenance, i.e. keeping the body in a good state, and for some physical activity. That means man's intermediary metabolism needs and uses ATP, by far the major source of energy that is required (Livesey, 1985). Monosaccharide SA and the hydrolysis products of higher saccharide SA when absorbed from the small intestine are, for the major part, per unit energy equally efficiently converted in ATP as glucose (Nutrition Council, 1987; Ziesenitz \& Siebert, 1987). However, mannitol after absorption, is slowly utilized so that at higher intakes most of it is excreted with the urine. It was assumed that at an intake of $20 \mathrm{~g} / \mathrm{d}$ or less half the absorbed mannitol would be excreted with the urine.

At intakes of $20 \mathrm{~g} \mathrm{SA} / \mathrm{d}$ or less in man absorption of the basal diet from the small intestine will not be negatively affected nor will lactate be an important product of fermentation in the colon. Thus, only the fate of VFA produced by the microbes has to be discussed (Livesey, 1985; Nutrition Council, 1987; Bergman, 1990). These VFA are easily absorbed and in intermediary metabolism the energy is readily trapped in ATP, of course by oxidation. From VFA $15-20 \%$ less ATP per $\mathrm{kJ}$ can be made than from glucose. This means that from SA fermented in the lower gut due to this lower energy 
production and energy losses with gases, fermentation heat and faeces per $\mathrm{kJ}$ only about $50 \%$ of the amount of ATP produced from absorbed glucose per $\mathrm{kJ}$ can be obtained by the body.

\section{THE NET ENERGY (NE; ATP) POTENTIAL OF SA}

Experimental determination of the NE content of $S A$. The experimental determination of the NE content of SA for man is extremely difficult. A major problem is the low level of intake of $20 \mathrm{~g} / \mathrm{d}$ or less required to prevent discomfort. At such low levels isotope labelling is often used with success. However, a direct determination of the NE content by, for example, labelling the carbon of the SA and measuring the excretion of $\mathrm{Clabel}$ does not give sufficient quantitative information. The $\mathrm{CO}_{2}$ is derived from both microbial and host metabolism and not all $\mathrm{C}$ compounds have the same energy potential. However, this method clearly shows the slower absorption and utilization of SA (Grimble et al. 1988).

A direct technique which is theoretically better is the energy balance experiment (Van Es et al. 1986). For higher precision a change-over design must be used, feeding in two balance experiments the same quantity of the same basal diet either with, for example, a given amount of sucrose or with the same amount of SA. Because of the inevitable errors the measured energy retention or heat production in each of the two experiments performed with the same subject has a standard deviation of 100-200 kJ, their difference

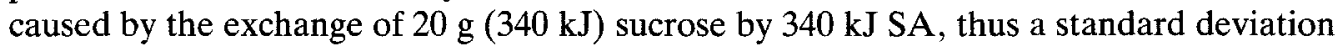
of $140-280 \mathrm{~kJ}$. Only by working with many subjects and replications can the influence of such errors be reduced sufficiently. Unfortunately, even this technique has further problems. For obvious reasons balance trials with man should not last too long. Therefore, there is a good chance that a subject's average digestion, physical activity, behaviour and degree of emotional stress are not the same in the two excretion collection (3-5 d) and gas exchange measurement (1-3 d) periods. Measuring physical activity and acclimatizing the subjects thoroughly to the experimental surroundings and routine can lower such errors to some extent but not completely.

In the one study completed so far, for lactitol $v$. sucrose at intakes of $50 \mathrm{~g} / \mathrm{d}$ a NE value of less than half that of sucrose was found, i.e. lower than theoretically expected (van Es et al. 1986). In the latter study with lactitol, $3 \mathrm{~g}$ aspartame $/ \mathrm{kg}$ was added to give it nearly the same sweet taste as sucrose. Recently Geissler \& James (1990) found in a study with twelve female subjects that after an overnight fast, intake of $24 \mathrm{mg}$ aspartame with water but no meal raised basal heat production by $6-8 \%$, the value being $2 \%$ with intake of water only. Thus, it is possible that in our lactitol study the aspartame addition was responsible for the very low NE value, but it cannot be excluded that the effect of aspartame on heat production might be different when given with a meal or may be related to sweetness which was balanced in our study.

Other calorimetric studies (Thiébaud et al. 1984) with man fed on SA or sucrose involved gas exchange measurements lasting only $6 \mathrm{~h}$, so $24 \mathrm{~h}$ energy balances could not be made. Their results also showed slow utilization of SA.

Instead of studies using man such energy balance experiments could be performed with animals which often tolerate higher levels of SA than man, although at the risk of a lower absorption of the SA and the basal diet and more fermentation if this is dose dependent. Unfortunately most animal species suited for such work have a digestive tract 
that differs from that of man, especially with regard to the location and extent of microbial fermentation (Ratcliffe, 1985; Henderson \& Demeyer, 1988; Giesecke, 1990). Moreover, pigs, rodents and poultry are not often fed on Western-type human diets which have a high fat content and digestibility.

Nevertheless, some of these animals have been used for estimating the NE content of SA for man (Berschauer, 1985; Nutrition Council, 1987). However, sufficient attention was not paid to these differences. Moreover, only a few complete energy balance trials and comparative slaughter trials (these with growing rather than adult animals) have been performed and variation in physical activity was incompletely assessed.

Experiments with man and animals in which only body-weight changes were measured have also been performed, but these do not give information suitable for our purpose. The energy content of such changes may vary considerably; moreover, their necessary long duration gives problems with strict compliance of the experimental routine.

The factorial method to estimate the NE content of $S A$. In the Netherlands the committee of the Nutrition Council (1987) concluded that the values obtained from the direct measurements of the NE content of SA with man and animal were too small in number, too imprecise or obtained with diets that differed too much from the usual human diet. It was preferable to evaluate all available information in a factorial way in relation to long-term intake by man of $20 \mathrm{~g} \mathrm{SA} / \mathrm{d}$ or less, and in comparison with a similar intake of sucrose. It was assumed that a SA intake of such a size would not change the absorption of the basal diet from the small intestine. The final conclusion was that from xylitol, sorbitol and mannitol 75,50 and $25 \%$ respectively is absorbed from the small intestine, whereas from maltitol $40 \%$ is absorbed as glucose and sorbitol, from isomalt $20 \%$ as glucose, sorbitol and mannitol (in proportion of $2: 1: 1$ ) and from lactitol $0 \%$. Half the absorbed mannitol was assumed to be excreted with the urine. All SA that entered the large intestine was assumed to have, per $\mathrm{kJ}$, half the $\mathrm{NE}$ content of sucrose. This gave $\mathrm{NE}$ contents per $\mathrm{g}$ dry matter without water of crystallization of $15,12 \cdot 5,8 \cdot 5,12,10$ and $8.5 \mathrm{~kJ}$ for xylitol, sorbitol, mannitol, maltitol, isomalt and lactitol respectively compared with $16.5 \mathrm{~kJ}$ for sucrose. It was remarked that more information on the percentage absorption from the small intestine and on the energy losses due to microbial fermentation were needed to increase the reliability of the predicted NE values. At intakes higher than $20 \mathrm{~g} / \mathrm{d}$ the NE content of SA would tend to decrease because of lower absorption of SA and basal diet from the small intestine and more microbial fermentation.

Most findings from recent studies, rather few in number, in general do not disagree with the estimates of the Nutrition Council (1987) committee. Only the human intubation studies of Beaugerie et al. (1991) give very high, instead of low, disappearance of sorbitol and maltitol from the small intestine but this may be due to the method used.

The concept of an EEC directive on the content of $S A$. Last September a committee of the European Economic Communities (1989) prepared a concept of a directive for member countries in which SA are given a NE content of $10 \mathrm{~kJ} / \mathrm{g}$ dry matter. Further experimental evidence has been demanded of producers of SA who claim a NE content for their product that differs from this value. It clearly is a compromise. In view of the fact that di- and oligosaccharide SA have to be hydrolysed before absorption from the small intestine it might have been better if some of these SA had been given at a slightly lower content than $10 \mathrm{~kJ} / \mathrm{g}$ and some monosaccharide SA at a slightly higher content.

Confirming that a given SA has a NE content other than $10 \mathrm{~kJ} / \mathrm{g}$ would require very 
expensive studies, at least consisting of many complete energy balance experiments with man. It is true that such studies, even when conducted on a smaller scale or depth, would have an important by-product: their results would improve our insight into the relationship between microbial fermentation in the digestive tract and health in man. However, funds for such studies could better be used for investigations that have this relationship, so important for our well-being, as their main aim. At the same time the knowledge gained could be used for further consolidation of the factorial method of estimating the NE content of SA.

\section{REFERENCES}

Beardsley, T. M. (1989). Sweet and sour. The secret of sweetness is in the shape. Scientific American 261, 12-13.

Beaugerie, L., Flourié, B., Marteau, P., Pellier, P., Franchisseur, C. \& Rambaud, J.-C. (1990). Digestion and absorption in the human intestine of three sugar alcohols. Gastroenterology 99, 717-723.

Bergman, E. N. (1990). Energy contributions of volatile fatty acids from the gastrointestinal tract in various species. Physiological Reviews 70, 567-590.

Berschauer, F. (1985). Die energetische Bewertung von partiell resorbierbaren Kohlenhydraten am Beispiel von Isomalt (Palatinit). (The energetic evaluation of partial resorbable carbohydrate, for example, of isomalt). In Die Verwertung der Nahrungsenergie durch Mensch und Tier, pp. 138-139 [C. Wenk, M. Kronauer, Y. Schutz and H. Bickel, editors]. Stuttgart: Wissenschaftliche Verlagsgesellschaft.

Birch, G. G. (1987). Chemical aspects of sweetness. In Sweetness, pp. 3-13 [J. Dobbing, editor]. London: Springer-Verlag.

Dowsett, J., Gibney, M. J. \& Kennedy, N. P. (1990). Bacterial fermentation occurs in the terminal ileum of ileostomists. Proceedings of the Nutrition Society 49, 110A.

Encyclopaedia Britannica (1987). Types and characteristics of sweeteners. Instant Research Service no. $3 R-2298$.

European Economic Communities (1989). Proposal for a Council Directive on Nutrition Labelling Rules for Foodstuffs Intended for Sale to the Ultimate Consumer, Article 4: Energy Values. Brussels: EEC.

Flourié, B. (1990). Personal information. Workshop on Sugar Alcohols. Brussels: International Life Sciences Institute.

Forbes, J. M. (1986). The Voluntary Food Intake of Farm Animals. Borough Green, Sevenoaks: Butterworth.

Geissler, C. A. \& James, D. A. (1990). Thermic effect of artificial sweeteners in humans: aspartame. Proceedings of the Nutrition Society 49, $19 \mathrm{~A}$.

Gibson, G. R., Cummings, J. H. \& Macfarlane, G. T. (1988). Use of a three-stage continuous culture system to study the effect of mucin on dissimulatory sulfate reduction and methanogenesis by mixed populations of human gut bacteria. Applied and Environmental Microbiology 54, 2750-2755.

Giesecke, D. (1990). Physiologische und biochemische Artunterschiede in Verdauung und Stoffwechsel. (Theological and biochemical differences between species in digestion and metabolism.) Advances in Animal Physiology and Animal Nutrition 20, 7-25.

Grimble, G. K. (1989). Fibre, fermentation, flora and flatus. Gut 30, 6-13.

Grimble, G. K., Patil, D. H. \& Silk, D. B. A. (1988). Assimilation of lactitol, an 'unabsorbed' disaccharide in the normal human colon. Gut 29, 1666-1671.

Grossklaus, R. (1985). Die 'kalorische Rettung' von unverdauten Kohlenhydraten im Kolon. (The 'caloric salvage' of undigestible carbohydrate in the colon.) In Die Verwertung der Nahrungsenergie durch Mensch und Tier, pp. 130-133 [C. Wenk, M. Kronauer, Y. Schutz and H. Bickel, editors]. Stuttgart: Wissenschaftliche Verlagsgesellschaft.

Gurr, M. I. (1990). The nutrition of microbes and man. British Journal of Nutrition 63, 5-6.

Henderson, C. \& Demeyer, D. I. (1988). The rumen as a model of the microbiology of fibre digestion in the human intestine. Proceedings of OECD Workshop 'Dietary Fibre in Monogastric Nutrition'. Ithaca: Cornell University.

James, Ph., Björntorp, P., Kare, M., Olson, R. E. \& Rosenberg, I. H. (1990). Summary of 13th Marabou Symposium on 'Factors influencing food intake in man'. Nutrition Reviews 48, 132-134. 
Nilsson, U. \& Jägerstad, M. (1987). Hydrolysis of lactitol, maltitol and Palatinit by human intestinal biopsies. British Journal of Nutrition 58, 199-206.

Nutrition Council (1987). The energy value of sugar alcohols. Recommendations of the Committee on Polyalcohols. The Hague: Voedingsraad.

Ratcliffe, B. (1985). The influence of the gut microflora on the digestive processes. In Proceedings of 3rd International Seminar on Digestive Physiology in the Pig. Report of National Institute of Animal Science, no. 580, pp. 245-267 [A. Just, H. Jørgensen and J. A. Fernandez, editors]. Copenhagen: Frederiksberg Bogtrykkeri.

Szylit, O. \& Charlet, G. (1981). Energy and protein retention in holoxenic, axenic and gnotoxenic chickens monoassociated with Lactobacillus spp. British Poultry Science 22, 305-315.

Thiébaud, D., Jacot, E., Schmitz, H., Spengler, M. \& Felber, J. P. (1984). Comparative study of isomalt and sucrose by means of continuous indirect calorimetry. Metabolism 33, 808-813.

Van Es, A. J. H., de Groot, L. \& Vogt, J. E. (1986). Energy balances of eight volunteers fed on diets supplemented with either lactitol or saccharose. British Journal of Nutrition 56, 545-554.

Van Weerden, E. J., Huisman, J., Hajee, C. A. J. \& van Kempen, G. J. M. (1989). The ileal passage of sorbitol in pigs. ILOB (Institute of Animal Nutrition and Physiology), Wageningen. Report no. I 89-3656. Wageningen: ILOB.

Van Weerden, E. J., Huisman, J. \& van Leeuwen, P. (1984). The digestion of Palatinit in the intestinal tract of the pig. $I L O B$ (Institute of Animal Nutrition and Physiology), Wageningen. Reports nos. 528 and 530. Wageningen: ILOB.

Würsch, P., Koellreutter, B., Gétaz, F. \& Arnaud, M. J. (1990). Metabolism of maltitol by conventional rats and mice and germ-free mice, and comparative digestibility between maltitol and sorbitol in germ-free mice. British Journal of Nutrition 63, 7-15.

Ziesenitz, S. C. \& Siebert, G. (1987). The metabolism and utilization of polyols and other bulk sweeteners compared with sugar. In Developments in Sweeteners - 3, pp. 109-149 [T. H. Grenby, editor]. London: Elsevier Applied Science. 